\title{
Evaluation of water salinity effects on the sea lice Lepeophtheirus salmonis found on farmed Atlantic salmon in Muchalat Inlet, British Columbia, Canada
}

\author{
G. Arriagada ${ }^{1}$, R. Vanderstichel ${ }^{1}$, H. Stryhn ${ }^{1}$, B., Milligan ${ }^{2}$, C.W. Revie ${ }^{1}$ \\ ${ }^{1}$ Centre for Veterinary Epidemiological Research, Department of Health Management, Atlantic Veterinary \\ College, University of Prince Edward Island, Charlottetown, PE C1A 4P3, Canada. \\ ${ }^{2}$ Grieg Seafood BC Ltd., 1180 Ironwood Street, Campbell River, BC V9W 5P7, Canada.
}

\begin{abstract}
The sea louse Lepeophtheirus salmonis is a major ectoparasite of both farmed and wild salmonids that causes substantial economic losses to the salmon industry worldwide. However, in British Columbia (BC) sea lice do not typically represent a significant health threat to farmed salmon. Sea lice patterns on Atlantic salmon farms in BC are not fully understood, but it is believed they are highly influenced by sea water salinity levels, which vary dramatically over the year. The objective of this investigation was to evaluate the effects of changes in water salinity on mobile L. salmonis found in farmed salmonids in the Muchalat Inlet, BC, while controlling for potential confounding factors. Using daily farm-based salinity measurements over a 13-year period, we built different salinity metrics to summarize salinity drops within specific periods of time prior to sea lice sampling events. Our results suggest that reduced salinity negatively impacted mobile sea lice in three different ways: first, a direct effect on mobile lice, lasting no more than 1 day; second, an effect mediated by detrimental impacts on pre-mobile lice stages; and third, an effect possibly associated with reduced fecundity of parents of that lice cohort. These findings confirm the important role of salinity on sea lice population dynamics in BC, and contribute new knowledge which is useful in understanding sea lice patterns and determinants in this region.
\end{abstract}

\section{Introduction}

The copepod Lepeophtheirus salmonis, commonly referred to as sea lice, is a major ectoparasite of both farmed and wild salmonids in the northern hemisphere; causing stress, reduced growth and poor feed-conversion efficiency. In cases of heavy infestation, fish death may also occur (Costello, 2006; Burka et al., 2012). The sea louse is considered a major health threat for the farmed salmon industry worldwide (Costello, 2009). In addition, there is concern about the potential negative impacts that lice originated from salmon farms may have on wild stocks in regions such as British Columbia (BC) and Norway where the salmon industries coexists with important populations of wild salmonids, although this is a question of active scientific debate (Brooks, 2005; Brooks \& Stucchi, 2006; Krkošek et al., 2007; Jackson et al., 2011; Krkošek et al., 2013).

Although L. salmonis is commonly reported on farmed Atlantic salmon in BC (Saksida et al., 2007a,b; 2011), sea lice do not represent a significant health threat to farmed salmon stocks in this region. Historically, damage as a result of sea lice infection has not been reported in this region, and veterinarians do not consider it to be an important disease (Saksida et al., 2007b). 
The main concern regarding sea lice in $\mathrm{BC}$, is the potential threat that parasites originating from farmed salmon may pose to wild Pacific salmonids (Morton et al., 2004; Saksida et al., 2011).

The annual temporal pattern of sea lice infestation on Atlantic salmon in BC is characterized by a consistent increase in autumn, and a marked decrease in summer (Saksida et al., 2007a,b; 2011; Marty et al. 2010). While it is believed the autumn increases are mostly due to the return of adult Pacific salmon to their natal rivers (Beamish et al. 2005; Saksida et al. 2006, 2007a; Marty et al. 2010), there is no clarity regarding the causes of the decline in summer. Treatments are certainly part of the reason, as these are often applied early in the year to minimize sea lice numbers on farms prior to wild juvenile out-migration as well as during the months of March to July when mandatory treatments are require whenever abundance is greater than 3 motile lice (Saksida et al., 2011). Nevertheless in many cases farms remain well within compliance levels in the absence of any treatment application and as such other factors (e.g. environmental) are likely responsible for the decreases observed.

Marine waters around the $\mathrm{BC}$ coast are characterized by marked seasonal variations in salinity, associated with important fresh water supplies originated from precipitation in winter and snow melting in spring (Beamish et al. 2006; Foreman et al. 2006). In light of the fact that experimental research has revealed that reduced salinity impairs survival and development of larvae, copepodids, chalimii (Johnson \& Albright, 1991; Tucker et al., 2000; Genna et al., 2005; Bricknell et al., 2006), and possibly mobile stages of L. salmonis (Wright et al., 2016), salinity variation is an obvious candidate to help explain sea lice dynamics in BC. This idea was explored by Brooks (2005) who used an oceanographic model to propose that reduced salinity waters in the Broughton Archipelago (which normally occur June through November) naturally controls sea lice dispersal in the area.

In general, observational studies have failed to reveal significant associations between $L$. salmonis abundance and salinity levels in BC and other regions (Saksida et al., 2007a; Jansen et al., 2012). In a review of research that has been conducted in BC, the authors note that the salinity data may have been insufficient in quantity, quality or variation to detect significant associations, and recommend using longer time series to understand the factors contributing to $L$. salmonis abundance on farmed Atlantic salmon (Saksida et al., 2015). More recently, an observational study found a positive, significant association between salinity levels and sea lice abundance on wild and captive salmon from BC (Rees et al., 2015). Complementarily, under the assumption that salinity negatively impacts sea lice survival, mathematical models have demonstrated that salinity has a key role on sea lice population dynamics (Rogers et al., 2013; Rittenhouse et al., 2016).

In this investigation we used a 13-year long record of daily salinity measurements at different depths taken on five salmon farms in Muchalat Inlet, British Columbia, with the objective of evaluating the water salinity effect on host-attached L. salmonis on farmed Atlantic salmon. By applying appropriate epidemiological approaches to these observational data, we hoped to gain a better understanding of sea lice patterns and determinants in this region.

\section{Material and methods}




\subsection{Study area}

This longitudinal study was conducted in Muchalat Inlet, a $55 \mathrm{~km}$ long inlet located on the west coast of Vancouver Island, British Columbia. This inlet harbours five fish farms, all rearing Atlantic salmon, and which belong to a single company. Farms in the Muchalat Inlet are relatively isolated from other salmon farms on Vancouver Island.

\subsection{Data}

The data used in this study were provided by the salmon farming company for each of the five fish farms that were active in the area at various times from 2003 to 2015. The data included information on sea lice, environmental, and production variables. Sea lice data were recorded at the cage level, typically once per month, and consisted of L. salmonis counts, classified as premobile stages (copepodids and chalimii), mobile stages (pre-adults and adult males), and adult females (with or without egg strings). Each month, 1 to 11 (mean=4) cages were sampled to estimate sea lice abundance. In general, when the monthly sampling included more than one cage, sea lice samples were not taken on the same day, but over a range of 2 to 25 days (mean=5). At each cage, a sample ranging from 19 to 101 fish (mean=21) was taken, fish were anesthetised, and the number of lice counted on each fish. Once recovered from anaesthesia, fish were placed back into the cage. The total number of lice was calculated by summing individual counts, and adding any detached parasites that were present in the tote used during counting. The associated number of sampled fish was also provided. Complementary information relating to oral delousing treatment events was also provided; this included treatment dates, cages treated, and the pharmaceutical agent administered.

The environmental data, namely water salinity and temperature, were recorded on a daily basis at each farm at 1, 5, 10, and 15 metre depths, whenever a site was active (i.e. when fish were present). Environmental measurements were typically taken prior to the morning feed, at around 8:00, and always at the same location on each site. Water salinity was recorded in parts per thousand (ppt) using an RHS-10ATC refractometer (Huake Instrument Co, Guangdong, China), and temperature in degrees Celsius $\left({ }^{\circ} \mathrm{C}\right)$ using an OxyGuard Handy Polaris portable meter, which have a precision of $+/-0.3 \mathrm{ppt}$ and $0.2^{\circ} \mathrm{C}$, respectively. Production variables, including mean fish weight and estimated total number of fish, were provided at the farm level on a daily basis. The start and end dates of each fish production cycle were inferred from these production variables.

\subsection{Study design}

Because, in most cases, sea lice sampling events were not repeated on the same cage each month, sea lice data from any single cage was sparse over time. Therefore, we collapsed sea lice data to the farm level by summing sea lice counts (and the number of fish sampled) across cages whose sampling dates were fewer than 6 days apart. This permitted us to work with all variables at the farm level.

The outcome of interest was the mobile lice mean abundance (lice per fish) at the farm level, which was calculated as the sum of the pre-adult, adult male, and adult female (gravid and nongravid) lice individual counts, divided by the total fish sampled.

Water salinity has been included in several observational studies aimed at modelling sea lice 
abundances. In general, the effect of salinity has been represented in these models by a single salinity record from the same day (or week) as the sea lice sampling event. As we were provided with daily salinity records, we had the opportunity to represent salinity in more elaborate ways, and to explore salinity effects not only on mature sea lice, but also on earlier life stages. To this end, we set four temporal windows before each sea lice sampling event over specific time points to match the developmental stages of the louse, according to the L. salmonis life cycle (Hayward et al., 2011; Hamre et al., 2013) and assuming a constant water temperature of $10^{\circ} \mathrm{C}$. For each window, we calculated a series of metrics aimed at summarizing the variability in salinity in different ways within these windows.

Based on the expected salinity effects on sea lice, these temporal windows were referred to as the short-, mid-, long-, and longer-term windows. The short-term window was placed from 0 to 15 days before the sea lice sampling event and was targeted at salinity impacts on mobile lice (preadult and adult groups). The mid-term window was from 16 to 45 days before a given sea lice sample; this 30-day window was targeted to represent salinity effects on pre-mobile lice (chalimus 1 and 2, and copepodids). The long-term window was 46 to 60 days prior to the sea lice sampling event, and it was intended to characterize salinity impacts on the free-swimming lice stages (nauplius 1 and 2 and eggs). Finally, the longer-term window was set from 61 to 75 days before a given sample to capture potential salinity effects on parents' fecundity.

For the short-term window, salinity levels were first summarized in three different forms: the arithmetic mean, the number of days that salinity levels dropped below a certain critical threshold; and the sum of daily salinity differences between a certain critical threshold and the recorded daily salinity (Eq. 1). Critical thresholds were set at 30, 20, and $15 \mathrm{ppt}$, according to research on the effect of reduced salinity on L. salmonis, which found $30 \mathrm{ppt}$ is the optimum salinity for sea lice development, while salinities in the range of 20 and 25 are debilitating and below 15 ppt are lethal (Bricknell et al., 2006). For example, for the threshold of $30 \mathrm{ppt}$, a daily salinity recording of 25 was equivalent to a drop of 5 units. Salinity values equal to or above the critical threshold were all set to zero. The sum of daily salinity drops below a certain critical threshold was calculated as follows:

$$
\sum_{d=1}^{n_{d}-1}\left(\tau-s a l_{d}\right)^{+}
$$

Where $n_{d}$ is the number of days in the current temporal window; $s a l_{d}$ is the water salinity at $d$ days before a given sea lice sample; and $\tau$ is the critical salinity threshold, which can take the values of 30,20 , or $15 \mathrm{ppt}$. The plus sign $(+)$ indicates that negative outcomes for $\left(\tau-s a l_{d}\right)$ were set to zero.

Because literature suggests that reduced salinity will have a rapid impact on mobile lice (from hours to a few days) (McLean et al., 1990; Powell et al., 2015; Wright et al., 2016), we explored the option of weighting salinity drops proportionally to the time between the date of the salinity drop and the date of the sea lice sample. To this end, we used a power distance weight function which gives higher weights to more recent salinity drop events (Eq. 2). By modifying its only parameter, alpha $(\alpha)$, we could redistribute the weights over the temporal window, allowing us to 
evaluate a range of scenarios. Consequently, in addition to the three salinity metrics mentioned above, we computed time-weighted versions for the sum of days that salinity levels dropped below a certain critical threshold and for the sum of daily salinity drops below a certain critical threshold. The time-weighted sum of daily salinity drops below a certain critical threshold was calculated as follows:

$$
\sum_{d=1}^{n_{d}-1} \frac{1}{d^{\alpha}}\left(\tau-s a l_{d}\right)^{+}
$$

Where $\alpha$ is a positive constant, which was assigned the values of $0.3,0.5,1.0,1.5,2.0$ or 3.0 .

In addition to that, daily salinity values observed on the sampling day and on one, two, three, four, and five days prior to a given sea lice sampling event were also analyzed in order to evaluate potential short-term salinity effects in a simpler way. A full description of the salinity metrics used in the study is presented in Table 1. For mid-, long-, and longer-term windows, the following salinity metrics were calculated: the arithmetic mean; the sum of days that salinity levels dropped below a certain critical threshold; and the sum of daily salinity drops below a certain critical threshold. Because these temporal windows were placed further from the sea lice sampling event, we did not expect that more recent salinity drops within those windows would have greater impacts on mobile lice counts than those further in time; consequently, timeweighted salinity metrics were not calculated for these three windows.

Other predictors were also incorporated in the analysis. Because water temperature was provided as a daily record (same as salinity) and we were interested in distinguishing its effect on different sea lice developmental stages, we calculated the mean temperature for each of the temporal windows described above. In addition, both the mean fish weight and the total number of fish on the farm on the day of the sampling event were explored, to control for fish age (i.e. exposure time) and host density, respectively. The effect of each in-feed delousing treatment was modeled as whether or not a treatment had been applied within a temporal window from 15 to 80 days before a given sea lice sample.

It is important to mention that observational studies based on sea lice monitoring data generally include preceding sea lice levels as a means of accounting for internal (i.e. within farm) sources of lice (Revie et al., 2003; Jansen et al., 2011; Kristoffersen et al., 2013). In this study, however, we did not include preceding sea lice samples as they may have acted as intervening variables (McKenzie et al., 2004); this is a factor that hampers the causal pathway between the exposure (i.e. salinity) and the outcome (i.e. mobile lice abundance), which might bias this relationship.

Finally, we explored whether any other farm-level conditions (different from those accounted for by predictors included already in the model) had an impact on sea lice abundance. To this end, we included the farm as a 5-level categorical predictor (or 'fixed' effect) in the model building process.

\subsection{Statistical model}

The mean mobile lice abundance was modeled using linear mixed effects models with fish 
production cycle as a random effect. In order to meet normality and homoscedasticity assumptions, we added an offset of 0.01 to each mobile lice mean abundance value before $\log$ transformation. In order to improve the model fit, we explored other offsets in the range of 0.001 and 0.1 , following the Box-Cox procedure described by Venables \& Ripley (2003), and a visual assessment of Q-Q plots of standardized residuals, once the final model was built. The Box-Cox procedure indicated that 0.05 was a suitable offset for the model. The model equation was expressed as:

$$
\ln \left(Y_{t c}+0.05\right)=X_{t c} \beta+u_{c}+\varepsilon_{t c} \quad \text { Eq. } 3
$$

where $Y_{t c}$ is the mobile lice mean abundance at time $t$ in a particular production cycle $c ; X_{t c}$ is the vector for fixed effects; $\beta$ is the corresponding coefficient vector, while $u_{c}$ is the random effect for fish production cycle, assumed to be independent and normally distributed, with mean zero and variance $\sigma^{2}$. Errors $\left(\varepsilon_{t c}\right)$ were assumed to be correlated due to repeated observations in time and, consequently, this equation component was modeled with an exponential correlation structure, in which the correlation is a function of time between sea lice samples.

\subsection{Model building and model validation}

We produced a preliminary model containing all relevant variables in the system, except for those representing salinity effects. This model was built following a stepwise backward elimination procedure. We then tested salinity metrics for the short-term window, one at a time, and recorded Akaike Information Criterion (AIC) estimates. For salinity metrics built upon a threshold, we chose $30 \mathrm{ppt}$ as the critical threshold value as a first option and, if significant, we tried the other two thresholds. The salinity metric associated with the lowest AIC was chosen for the next step. A similar procedure was carried out for salinity metrics in the rest of the temporal windows. A preliminary assessment of the data revealed that salinity showed promising associations with the outcome when metrics taken at 1 and 5 metre depths were used. This was in line with expectations as the lower and more variable levels of salinity tended to be observed at these depths (Figure 3a). This being the case, the procedure described above was replicated only for salinities recorded at depths of 1 and 5 metres, producing two final candidate models. The final model was chosen between these two based on statistical (AIC) and biological criteria.

During the model building process, the least significant predictors were removed from the model, one at a time, until all remaining variables were significant (Wald test $p<0.05$ ), unless a change greater than $30 \%$ in the coefficients of other predictors was observed. Models were fitted using maximum likelihood (ML) estimation. When two highly collinear predictors were detected $(|r|>0.7, \mathrm{r}=$ Pearson correlation coefficient), the one making more biological sense was kept in the model. Model coefficients were standardized to enable a direct comparison of the magnitudes of effects for predictors, by converting each variable in the final model to Z-scores. Linearity between continuous predictors and the outcome was assessed by including quadratic terms. If the latter was significant, the quadratic form of the predictor was retained in the model. Normality of error terms was evaluated by a Q-Q plot using standardized residuals, while homoscedasticity was examined by plotting standardized residuals vs. fitted values. All statistical analyses were performed with Stata, version 13 (StataCorp LP). 


\section{Results}

\subsection{Descriptive results}

Sites in the study area became active in different years. The first one began in 2003 and, by 2008, all five farms were active. Farms contributed data from 3 to 6 production cycles during the study period, separated by fallowing breaks of variable duration. Table 2 summarizes the years with active production for each farm during the study period. Figure 1 depicts the study area and the geographic location of each farm in Muchalat Inlet.

(Table 2)

(Figure 1)

Participating farms contributed a total of 444 farm-level sea lice sampling events during the study period, with a minimum of 75 and a maximum of 106 per individual farm. The overall median lice per fish was $0.000(\mathrm{SD}=0.252)$ for pre-mobiles, and $0.483(\mathrm{SD}=1.385)$ for total mobiles (Table 3). Mean sea lice levels in the two groups varied across farms, although there were no particular farms with consistently higher or lower sea lice levels over time. In general, mean mobile levels were more similar across farms over time than pre-mobile stages. The temporal pattern of mobile lice at individual farms was characterized by sporadic short-term peaks (Figure 2). All farms reported 1 or 2 delousing treatments per production cycle, totalling 34 procedures. In all cases, the drug used was emamectin benzoate (EMB) which is administered to fish through feed. Typically, cage-level treatments lasted from 5 to 9 days (mean: 6.9 days), during which period all cages on a farm were treated simultaneously.

\section{(Table 3)}

Water salinity showed high daily variability over time. In most cases, the daily change was not greater than $6 \mathrm{ppt}$, but it reached up to a $22 \mathrm{ppt}$ difference. Figure 2 presents a sample of this variability, depicting daily salinity smoothed (Alpha $=0.05$ ) records measured at a 5 metre depth on farm F5 from 2005 to 2014. The standard deviation (SD) reveals that the variability of salinity levels was greatest at 1 metre depth and decreased markedly as depth increased (Table 4). The lowest mean salinity was recorded at 1 metre depth $(20.3 \mathrm{ppt})$ and increased with depth. Although the salinity range was practically the same at the four depths $(\sim 2$ to $36 \mathrm{ppt})$, the interquartile range indicates that a large proportion of the values below $15 \mathrm{ppt}$ were measured at the 1 metre depth (Table 4). Salinity also exhibited a seasonal pattern, with spring and early winter associated with drops in salinity. Seasonality was more evident at shallower depths, reflecting the fact that more stable values tended to be recorded as depth increased. These seasonal patterns are clearly observable in Figure 3a, showing smoothed salinity curves (Alpha $=$ 0.12) at 1, 5, 10, and 15 metre depths for farm F3 from December 2013 to December 2014. Seasonal patterns of salinity in other years and farms were similar to those shown in Figure 3a.

Water temperature also exhibited a marked seasonal pattern, characterized by lower temperatures between January and March, and higher records in July and August (Figure 2). Differences in temperature displayed less variability at greater depths as might be expected due to the fact that sea water temperature changes tend to be driven by air-sea interactions. Temperature profiles 
recorded across depths, on farm F3 from December 2013 to December 2014, provide a typical example of these patterns (Figure 3b). Mean temperatures demonstrated an inverse association with depth, although the difference in mean temperatures measured at 1 and 15 metre depths was less than one degree $\left(11.2\right.$ versus $\left.10.4^{\circ} \mathrm{C}\right)$. The overall temperature range was from 1.2 to $19.6^{\circ}$ $\mathrm{C}$, and remained similar across the four depths. There is also typically variation in sea water temperature within a given 24 hour period; however, as our environmental sampling was carried out in the early morning of each day this variation is not evident in the data analysed here.

Fish were observed throughout the whole production cycle. The $90 \%$ range of mean fish weight, associated with sea lice sampling events, was from $173 \mathrm{~g}$ to $5.3 \mathrm{~kg}$. In the case of the total number of fish on a farm, $90 \%$ of the observations ranged from 245,000 to $1,160,000$ individuals.

\subsection{Modelling of salinity effects}

The model building procedure was carried out for metric values taken at both the 1 and 5 metre depths, producing two candidate models. For salinity at 1 metre, the lowest AIC estimate was achieved by including the salinity level recorded on the same day as the sea lice sampling event for the short-term window, and the mean salinity for the mid- and the longer-term windows. Table 5 presents the AIC values associated with models built using metrics from the 1 metre depth. In the model built on salinity at 5 metres, the best fit was obtained with the salinity level recorded the same day as the sea lice sampling event for the short-term window, and the mean salinity in the mid-term window. When the two candidate models were compared, the model built on 1 metre salinity records achieved the lowest $\mathrm{AIC}$ value $(\triangle \mathrm{AIC}=6.9, \mathrm{n}=278)$ and, therefore, was selected as the final model.

The final model, presented in Table 6, indicates that the salinity level recorded the same day as the sea lice sampling event presented a positive, significant association with the log mobile sea lice abundance $(p=0.006)$. For each salinity unit drop (i.e. $1 \mathrm{ppt})$, the count of total mobile lice decreased by $1.7 \%$. Mean salinity levels, from both 15 to 45 and 61 to 75 days before the sea lice sampling event also showed a positive and significant association with mobile lice counts $(p<0.001$, and $p=0.022$, respectively). Mobile lice abundance decreased by 6.3 and $2.3 \%$ for each mean salinity unit drop within these two temporal windows. Correlations between salinity metrics in the final model were not greater than 0.4 .

The mean water temperature effect was only significant in the longer-term window $(p=0.034)$, from 61 to 75 days before the sea lice sampling event. This association was positive, indicating mobile lice increased by $7 \%$ per each additional mean temperature unit $\left({ }^{\circ} \mathrm{C}\right)$ in this time period.

The mean fish weight exhibited a positive association with the mobile sea lice mean abundance $(p=0.040)$, which indicates that fish are more likely to become more infected as they become larger, or have spent more time at sea, with abundance increasing, on average, by $12 \%$ for each additional $\mathrm{kg}$ of weight.

Delousing treatments with EMB occurring within 15 to 80 days before the sampling day were negatively associated with sea lice levels $(p=0.003)$. Whenever an EMB treatment was reported in that temporal window, mobile lice abundance was 35\% lower. 
The autocorrelation for error terms one day apart was estimated to be 0.973 .

In terms of standardized coefficient estimates, the effect of mean salinity from 15 to 45 days before the sea lice sampling was 2.5 times greater than both salinity recorded on the same day as the sea lice sampling event, and mean salinity from 61 to 75 days prior the sampling event. In an intermediate range, the magnitude of effects of mean temperature from 61 to 75 days before the sampling, mean fish weight, and EMB treatment were equivalent, although the latter exhibited a negative relationship with the outcome.

In none of the models we built did the specific farm site (included as a fixed predictor) produce a significant association with mobile lice abundance.

\section{Discussion}

In this study we explored the effects of sea water salinity on mobile L. salmonis stages on farmed Atlantic salmon in Muchalat Inlet, British Columbia. To that end, we modeled mobile lice abundance as a function of different salinity metrics built for 4 temporal windows set prior each sea lice sampling events, to match the developmental stages of lice. We also included in the analysis other environmental factors such as water temperature and production variables. While the farms' sea lice counting protocol also requires the enumeration of Caligus species, none were recorded in the data set explored. This is consistent with the very infrequent observation of $C$. clemensi on wild smolts sampled in the same area (Elmoslemany et al., 2015) and may indicate that Caligus species are more sensitive to low salinities, though this species imbalance was not observed elsewhere in BC (Patanasatienkul et al., 2013).

The best explanatory salinity metrics for the final model were selected in a best-model-fit basis, using statistical criteria (i.e. AIC). The top ranked model included significant salinity effects for the short-, long-, and longer-term windows, suggesting salinity impacted mobile lice at three particular intervals of time.

According to the final model, the more acute salinity effect occurred on the same day as the sea lice sampling event. A similar interpretation can be made on the resulting AIC estimates of models including time-weighted sum of daily salinity drops below $30 \mathrm{ppt}$. Among this group of models, the one using alpha $=3.0$ achieved the highest fit, indicating the impact of salinity level on the sampling day was more important than the impact of salinity levels a few days before. Furthermore, the AIC of that model was practically the same as the AIC of the final model, which means reduced salinity one or more days later did not add any additional effect on mobile lice over the effect of salinity recorded the same day as the sea lice sampling. Consistent with that, models including salinity metrics for the short-term window, assigning equal weights for daily salinity records (i.e. salinity mean), achieved lower model fit. These findings suggest that a drop in salinity has an acute, short-term impact on mobile L. salmonis.

Research addressing the effect of reduced salinity on sea lice survival and development is relatively scarce. However, efficacy evaluation of "freshwater treatments" (typically $<5 \mathrm{ppt}$ ) for sea lice control has provided new information about the impact on sea lice exposed to null or 
very low salinity water. Overall, research has found that reduced salinity has a detrimental effect on sea lice, mainly driven by mortality, and that this effect is more marked in early stages (planktonic and infective copepodid) than in more mature stages (Hahnenkamp, 1985; Bricknell et al., 2006; Wright et al., 2016).

Research conducted to evaluate the effect of freshwater on host-attached L. salmonis has found that most adult lice died after 3-4 days of continuous exposure to freshwater, although some individuals survived up to 7-8 days (Hahnenkamp, 1985; McLean et al., 1990). A recent investigation reported that pre-adult and mature female lice numbers were significantly reduced immediately after a 3-hour freshwater treatment in a well boat (Powell et al., 2015), indicating that low salinity acts quickly on mobile lice. These results are consistent with our findings in terms of the relatively rapid impact of low salinity on mobile lice. As is the case for salmonids in their seawater phase, sea lice are susceptible to osmotic stress when salinity is reduced, which is ultimately the cause of louse death. However, it has been suggested that host-attached adults may reduce the salt loss through ion intake from the consumption of fish tissue or that the fish mucus in which they are embedded may act as a barrier (Stone et al., 2002). In addition, low salinity adaptation has been reported for the mature female stage of Caligus rogercresseyi (Bravo et al., 2008), which may also occur in L. salmonis. These factors, among others, could help explain why some experimental studies reported non-significant reductions in adult lice counts after freshwater exposure (Stone et al., 2002; Wright et al., 2016).

The second salinity effect on mobile lice was associated with reductions in the mean salinity levels observed from 15 to 45 days prior each sea lice sampling event. Based on the L. salmonis life cycle, estimated development time (Hayward et al., 2011; Hamre et al., 2013), and assuming a constant water temperature of $10{ }^{\circ} \mathrm{C}$, we can presume most adult lice observed at a given sampling event would likely have been in the copepodid, chalimus 1, or chalimus 2 stage during the 15-45 days prior to sampling. Given previous research found that pre-mobile L. salmonis stages are particularly susceptible to low salinity or freshwater (Tucker et al., 2000; Bricknell et al., 2006; Powell et al., 2015; Wright et al., 2016), our findings could be interpreted as salinity having an impact on the pre-mobile abundance, which is then later seen to reduce adult lice counts. Salinity expressed as the sum of daily salinity drops below $30 \mathrm{ppt}$ produced a model with a similar fit as our final model, which makes sense as it captures daily variability in a similar way to mean salinity. The sum of days that salinity dropped below $30 \mathrm{ppt}$ produced models with poorer fit than our final model, possibly because it did not capture the severity of daily salinity deviations from the set threshold (i.e. $30 \mathrm{ppt}$ ).

The third salinity effect was represented by the mean salinity recorded from 61 to 75 days before the sea lice sampling event. This temporal window likely corresponds to the time period when observed mobile lice were conceived, and suggests that reduced salinity during this period, negatively impacted the fecundity of the parents of that cohort. There is only one published study on salinity and sea lice fecundity, conducted in Chile on C. rogercresseyi from farmed Atlantic salmon (Bravo et al., 2009), who reported large gravid females and high numbers of eggs per string in areas of low salinity. These appear to be inconsistent with the results presented here, however the study in Chile relates to a different species of sea louse and the statistical methods employed were rudimentary. 
The temporal window set to capture a potential salinity effect on planktonic lice stages was not significant in the final model, suggesting that salinity did not affect these early stages in our case. This finding contrasts with most of the research done on reduced salinity and its impact on freeswimming L. salmonis stages, which found that survival and development of planktonic lice stages, as well as settlement rates of copepodids on the host, depend heavily on optimal salinity levels (i.e. at least 30 ppt) (Hahnenkamp, 1985; Johnson \& Albright, 1991; Brooks, 2005; Genna et al., 2005; Bricknell et al 2006). We hypothesise that the most likely reason for this disagreement lies in the fact that our study used different methodological approaches than previous studies on this matter. While previous research assessed the effect of reduced salinity on planktonic lice stages in a direct way; this is using planktonic stages as the study outcome, we attempted to capture this association through the evaluation of adult lice stages, which is an indirect way. Another possible reason of this discrepancy is that previous research addressing these matters has mostly used the experimental setting, while, in our case, we have pursued an observational framework, which is more prone to the effect of confounding factors. The association between reduced salinity and free-swimming lice stages may have been confounded in our case by the action of factors not included in our analysis, such as external sources of sea lice.

Among models including salinity metrics based on a critical threshold, models using $30 \mathrm{ppt}$ as the threshold consistently achieved better fit than models based on $20 \mathrm{ppt}$ and, in turn, these were superior to models using $15 \mathrm{ppt}$. This may have been due, at least in part, to the fact that salinity values above the threshold were converted to zero, and as such, lower thresholds had smaller deviances compared to higher thresholds, which ultimately reduced the variability of the salinity metric.

Standardized coefficient estimates suggest that the greatest salinity impact on mobile lice abundance was exerted through a detrimental effect on pre-mobile stages (i.e. copepodid, chalimus 1 and 2). This effect was 2.5 times larger than both the direct salinity effect on mobile lice (i.e. short-term effect), and the salinity effect mediated through reduction of progenitors' fecundity (i.e. longer-term effect). This means that, among salinity effects indentified in our final model, pre-mobile lice were more sensitive to reduced salinity than mobile stages, which agrees with experimental research on these matters (Hahnenkamp, 1985; Bricknell et al., 2006; Wright et al., 2016).

The important role of water temperature on sea lice survival and development is well known (Johnson \& Albright, 1991; Tucker et al., 2002; Stien et al., 2005; Groner et al., 2014). Consequently, we included the mean water temperature for each of the temporal windows used to evaluate the effects of salinity. The only significant effect from water temperature was observed on the longer-term windows, suggesting that water temperature may have an impact on the fecundity of the preceding lice cohort. Previous experimental research found that lice subjected to lower temperatures had longer egg strings and a greater numbers of eggs, but with smaller eggs with reduced survivability (Heuch et al., 2000), which might explain our findings. Admittedly, we might have expected water temperature, which is known to exhibit an influence on developmental times of sea lice, to have a stronger short-term impact on abundance, with the slower developmental times in colder waters resulting in fewer mobile lice. However, even the fit for models including mean temperature in the longer-term window and the model without any 
temperature metric was very similar (i.e. $\triangle \mathrm{AIC}=2.1$ ), suggesting water temperature may play a minor role in our modelling framework. As such it will be important that future research investigates more completely the potential interactions between salinity and sea water temperature on sea lice development (Groner et al, 2016) at various temporal scales.

Other predictors of importance were the presence of sea lice treatments and mean fish weight. With regard to treatments, the final model indicates that mobile lice abundance reduced by a rate of $35 \%$ when an EMB treatment was administered from 15 to 80 days before the sampling event. This finding provides additional observational evidence that EMB treatments continue to be effective in reducing sea lice levels in $\mathrm{BC}$, which is consistent with earlier observational and experimental work (Saksida et al., 2010; 2013). Mean fish weight was included in the final model as a way to adjust for different size and/or age of the fish. The effect of mean fish weight on mobile lice abundance was positive, which was expected, and is consistent with other research results (Tucker et al., 2002; Jansen et al 2012; Kristoffersen et al., 2013); however, its significance level was weak, indicating its role was marginal in our system.

Contrary to expectations, sea lice abundance did not significantly vary across farms, after accounting for on-site managerial and environmental factors. This indicates there were no other farm-level factors that significantly impacted mobile lice abundance. Although considerable spatial variation in sea lice levels has been previously reported in BC (Saksida et al., 2007b), it is possible that a highly spatial-structured predictor, such as salinity, has removed the majority of the variation in observed sea lice levels among farms (Table 3). This seems feasible as a recent study of sea lice on wild salmon in the same area revealed that much of the observed spatial variation could be explained by salinity levels (Elmoslemany et al., 2015).

Previous observational research on determinants of sea lice abundance considered the inclusion of water salinity, but few of them found significant salinity effects (e.g. Heuch et al., 2009). Most of these observational studies included salinity levels during the same week (or a similar temporal scale) that their samples were taken, so they were able to test only short-term salinity effects. In the current study, we took advantage of daily salinity records measured on-site to build a variety of salinity impact metrics, in an attempt to capture salinity effects at different periods.

Before closing this discussion it is perhaps worth providing a word of caution. Given the number of salinity metrics evaluated in this study, for various temporal windows, depths, and thresholds, we ran the risk of over-fitting our data and increasing Type I error (with significance levels being higher than nominal due to multiple testing). Our results show estimated relations determined from an exploratory analysis, and validation with data from future studies is required to confirm the effects of these salinity metrics. In line with our study aims, of evaluating the effects of sea water salinity on host-attached L. salmonis of farmed Atlantic salmon, we did not have specific pre-defined hypotheses. As such our results should not be taken as 'proving' specific relationships, but rather as identifying interesting salinity metrics, which could be included in future studies and in the process lead to a better understanding of determinants of sea lice dynamics in this region.

This work constitutes the first attempt to explain the role of sea water salinity on host-attached $L$. salmonis, in farmed Atlantic salmon, based on an observational study. We have made explicit 
efforts to characterize short-term salinity effects, but have also provided evidence of longer term salinity effects, likely driven by the impact of salinity on pre-mobile stages, and possibly on the fecundity of parents of the lice cohort observed in the sea lice sampling events. Our findings provide new insights for the understanding of L. salmonis dynamics in British Columbia, and strengthen the idea introduced by Brooks (2005) that salinity may act as a 'natural' control factor in $\mathrm{BC}$ under certain conditions. In terms of practical implications, our findings may suggest that there could be synergisms between salinity drops (which can be forecasted) and other sea lice control metrics, such as targeted pharmacological treatments. Knowing how these are likely to interact may help farmers decide on the most suitable timing of treatments and, in so doing, ultimately increase treatment efficacy.

\section{Acknowledgements}

The authors would like to thank the Canada Excellence Research Chair (CERC) in Aquatic Epidemiology for funding this research and to Grieg Seafood BC Ltd. for providing the data for this investigation.

\section{References}

Beamish, R.J., Jones, S., Neville, C.M., Sweeting, R., Karreman, G., Saksida, S., Gordon, E., 2006. Exceptional marine survival of pink salmon that entered the marine environment in 2003 suggests that farmed Atlantic salmon and Pacific salmon can coexist successfully in a marine ecosystem on the Pacific coast of Canada. ICES J. Mar. Sci. 63, 1326-1337.

Beamish, R.J., Neville, C.M., Sweeting, R.M., Ambers, N., 2005. Sea lice on adult Pacific salmon in the coastal waters of central British Columbia. Fish. Res. 76, 198-208.

Bravo, S., Erranz, F., Lagos, C., 2009. A comparison of sea lice, Caligus rogercresseyi, fecundity in four areas in southern Chile. J. Fish Dis. 32, 107-113.

Bravo, S., Pozo, V., Silva, M.T., 2008. The tolerance of Caligus rogercresseyi to salinity reduced in southern Chile. Bull. Eur. Ass. Fish Pathol. 28, 198-206.

Bricknell, I.R., Dalesman, S.J., O'shea, B., Pert, C.C., Luntz, A.J.M., 2006. Effect of environmental salinity on sea lice Lepeophtheirus salmonis settlement success. Dis. Aquat. Org. 71, 201-212.

Brooks, K., 2005. The effects of water temperature, salinity, and currents on the survival and distribution of the infective copepodid stage of sea lice (Lepeophtheirus salmonis) originating on Atlantic salmon farms in the Broughton Archipelago of British Columbia, Canada. Rev. Fish Sci. 13, 177-204.

Brooks, K.M., Stucchi, D.J., 2006. The effects of water temperature, salinity, and currents on the survival and distribution of the infective copepodid stage of sea lice (Lepeophtheirus salmonis) originating on Atlantic salmon farms in the Broughton Archipelago of British Columbia, Canada (Brooks, 2005) - A response to rebuttal of Krkošek et al. Rev. Fish Sci. 14, 13-23.

Burka, J.F., Fast, M.D., Revie, C.W., 2012. Lepeophtheirus salmonis and Caligus rogercresseyi. In: Woo, P.T.K., Buchmann, K. (Eds.), Fish Parasites: Pathobiology and Protection. Wallingford, Oxfordshire, 
Cambridge, MA: CABI, pp. 350-370.

Costello, M.J., 2006. Ecology of sea lice parasitic on farmed and wild fish. Trends Parasitol. 22, 475-483.

Costello, M.J., 2009. The global economic cost of sea lice to the salmonid farming industry. J. Fish Dis. $32,115-118$.

Elmoslemany, A., Revie, C.W., Milligan, B., Stewardson, L., Vanderstichel, R., 2015. Wild juvenile salmonids in Muchalat Inlet, British Columbia, Canada: factors associated with sea lice prevalence. Dis. Aquat. Org. 117, 107-120.

Foreman, M.G.G., Stucchi, D.J., Zhang, Y., Baptista, A.M. 2006. Estuarine and tidal currents in the Broughton Archipelago. Atmos.-Ocean 44, 47-63.

Genna, R.L, Mordue, W., Pike, A.W., Mordue (Luntz), A.J., 2005. Light intensity, salinity, and host velocity influence presettlement intensity and distribution on hosts by copepodids of sea lice, Lepeophtheirus salmonis. Can. J. Fish. Aquat. Sci. 62, 2675-2682.

Groner, M.L., Gettinby, G., Stormoen, M., Revie, C.W., Cox, R., 2014. Modelling the impact of temperature-induced life history plasticity and mate limitation on the epidemic potential of a marine ectoparasite. PLoS ONE 9, e88465.

Groner M.L., McEwan G.F., Rees E.E., Gettinby G.. Revie C.W. (2016) Quantifying the influence of salinity and temperature on the population dynamics of a marine ectoparasite. Can. J. Fish. Aquat. Sci. 73, 1-11. doi: 10.1139/cjfas-2015-0444

Hahnenkamp, L., 1985. The osmotic response of the salmon louse, Lepeophtheirus salmonis, during transition from freshwater to seawater. J. Comp. Physiol., B. 155, 357-365.

Hamre, L.A., Eichner, C., Caipang, C.M.A., Dalvin, S.T., Bron, J.E., Nilsen, F., Boxshall, G., SkernMauritzen, R., 2013. The salmon louse Lepeophtheirus salmonis (Copepoda: Caligidae) life cycle has only two chalimus stages. PLoS ONE 8, e73539.

Hayward, C.J., Andrews, M., Nowak, B.F., 2011. Introduction: Lepeoptheirus salmonis - a remarkable success story. In: Jones, S., Beamish, R. (Eds.), Salmon Lice: An Integrated Approach to Understanding Parasite Abundance and Distribution. Wiley-Blackwell, Chichester, UK, pp. 1-28

Heuch, P.A., Nordhagen, J.R., Schram, T.A., 2000. Egg production in the salmon louse [Lepeophtheirus salmonis (Krøyer)] in relation to origin and water temperature. Aquac. Res. 31, 805-814.

Heuch, P.A., Olsen, R.S., Malkenes, R., Revie, C.W., Gettinby, G., Baillie, M., Lees F., Finstad, B., 2009. Temporal and spatial variations in lice numbers on salmon farms in the Hardanger fjord 2004-06. J. Fish Dis. 32, 89-100.

Jackson, D., Cotter, D., ÓMaoiléidigh, N., O’Donohoe, P., White, J., Kane, F., Kelly, S., McDermott, T., McEvoy, S., Drumm, A., Cullen, A., 2011. Impact of early infestation with the salmon louse Lepeophtheirus salmonis on the subsequent survival of outwardly migrating Atlantic salmon smolts from a number of rivers on Ireland's south and west coasts. Aquaculture 319, 37-40.

Jansen, P.A., Kristoffersen, A.B., Viljugrein, H., Jimenez, D., Aldrin, M., Stien, A., 2012. Sea lice as a density-dependent constraint to salmonid farming. Proc. R. Soc. Lond., B 279, 2330-2338. 
Johnson, S.C., Albright, L.J., 1991. The developmental stages of Lepeophtheirus salmonis (Krøyer, 1837) (Copepoda: Caligidae). Can. J. Zool. 69, 929-950.

Kristoffersen, A.B., Rees, E.E., Stryhn, H., Ibarra, R., Campisto, J.L., Revie, C.W., St-Hilaire, S., 2013. Understanding sources of sea lice for salmon farms in Chile. Prev. Vet. Med. 111, 165-175.

Krkošek, M., Ford, J.S., Morton, A., Lele, S., Myers, R.A., Lewis, M.A., 2007. Declining wild salmon populations in relation to parasites from farm salmon. Science 318, 1772-1775.

Krkošek, M., Revie, C.W., Gargan, P.G., Skilbrei, O.T., Finstad, B., Todd, C.D., 2013. Impact of parasites on salmon recruitment in the Northeast Atlantic Ocean. Proc. R. Soc. B Biol. Sci. 280, 20122359.

McKenzie, E., Gettinby, G., McCart, K., Revie, C.W., 2004. Time series models of sea lice Caligus elongatus (Nordmann) abundance on Atlantic salmon Salmo salar L. in Loch Sunart, Scotland. Aquac. Res., 35, 764-772.

McLean, P.H., Smith, G.W., Wilson, M.J., 1990. Residence time of the sea louse, Lepeophtheirus salmonis, on Atlantic salmon, Salmo salar L., after immersion in freshwater. J. Fish Biol. 37, 311-314.

Morton, A., Routledge, R., Peet C., Ladwig, A., 2004. Sea lice (Lepeophtheirus salmonis) infection rates on juvenile pink (Oncorhynchus gorbuscha) and chum (Oncorhynchus keta) salmon in the nearshore marine environment of British Columbia, Canada. Can. J. Fish. Aquat. Sci. 61, 147-157.

Patanasatienkul T., Sanchez J., Rees E.E., Krkošek M., Jones S.R.M., Revie C.W., 2013. Sea lice infestations on juvenile chum and pink salmon in the Broughton Archipelago, Canada from 2003 to 2012. Dis. Aquat. Org. 105, 149-161.

Powell, M.D., Reynolds, P., Kristensen, T., 2015. Freshwater treatment of amoebic gill disease and sealice in seawater salmon production: Considerations of water chemistry and fish welfare in Norway. Aquaculture 448, 18-28.

Rees, E.E., St-Hilaire, S., Jones, S.R.M., Krkošek, M., DeDominicis, S., Foreman, M.G.G., Patanasatienkul, T., Revie, C.W., 2015. Spatial patterns of sea lice infection among wild and captive salmon in western Canada. Landscape Ecol. 30, 989-1004.

Revie, C.W., Gettinby, G., Treasurer, J.W., Wallace, C., 2003. Identifying epidemiological factors affecting sea lice Lepeophtheirus salmonis abundance on Scottish salmon farms using general linear models. Dis. Aquat. Org. 57, 85-95.

Rittenhouse, M.A., Revie, C.W., Hurford, A., A model for sea lice (Lepeophtheirus salmonis) dynamics in a seasonally changing environment. Epidemics 16, 8-16.

Rogers, L.A., Peacock, S.J., McKenzie, P., DeDominicis, S., Jones, S.R.M., Chandler, P., Foreman, M.G.G., Revie, C.W., Krkošek, M., 2013. Modeling parasite dynamics on farmed salmon for precautionary conservation management of wild salmon. PLoS ONE 8, e60096.

Saksida, S., Bricknell, I., Robinson, S., Jones, S., 2015. Population ecology and epidemiology of sea lice in Canadian waters. DFO Can. Sci. Advis. Sec. Res. Doc. 2015/004. v + 34 p. 
Saksida, S., Constantine, J., Karreman, G.A., Donald, A., 2007a. Evaluation of sea lice abundance levels on farmed Atlantic salmon (Salmo salar L.) located in the Broughton Archipelago of British Columbia from 2003 to 2005. Aquac. Res. 38, 219-231.

Saksida, S., Karreman, G., Constantine, J., Donald, A., 2007b. Differences in Lepeophtheirus salmonis abundance levels on Atlantic salmon farms in the Broughton Archipelago, British Columbia, Canada. J. Fish Dis. 30, 357-366.

Saksida, S., Morrison, D., McKenzie, P., Milligan, B.Downey, E., Boyce, B., Eaves, A., 2013. Use of Atlantic salmon, Salmo salar L., farm treatment data and bioassays to assess for resistance of sea lice, Lepeophtheirus salmonis, to emamectin benzoate (SLICE®) in British Columbia, Canada. J. Fish Dis. 36, 515-520.

Saksida, S., Morrison, D., Revie, W., 2010. The efficacy of emamectin benzoate against infestations of sea lice, Lepeophtheirus salmonis, on farmed Atlantic salmon, Salmo salar L., in British Columbia. J. Fish Dis. 33, 913-917.

Saksida, S., Morrison, D., Sheppard, M., Keith, I., 2011. Sea Lice Management on Salmon Farms in British Columbia, Canada. In: Jones, S., Beamish, R. (Eds.), Salmon Lice: An Integrated Approach to Understanding Parasite Abundance and Distribution. Wiley-Blackwell, Chichester, UK, pp. 235-278.

Stien, A., Bjorn, P.A., Heuch, P.A., Elston, D.A., 2005. Population dynamics of salmon lice Lepeophtheirus salmonis on Atlantic salmon and sea trout. Mar. Ecol. Prog. Ser. 290, 263-275.

Stone, J., Boyd, S, Sommerville, C, Rae, G.H., 2002. An evaluation of freshwater bath treatments for the control of sea lice, Lepeophtheirus salmonis (Krøyer), infections in Atlantic salmon, Salmo salar L. J. Fish Dis. 25, 371-373.

Stucchi, D.J., Guo, M., Foreman, M.G.G., Czajko, P., Galbraith, M., Mackas, D.L., Gillibrand, P.A., 2011. Modeling sea lice production and concentrations in the Broughton Archipelago, British Columbia. In: Salmon Lice: An Integrated Approach to Understanding Parasite Abundance and Distribution (ed. by S. Jones \& R. Beamish), pp. 117-150. John Wiley \& Sons, Ltd., Chichester, UK.

Tucker, C.S., Sommerville, C., Wootten, R., 2000. The effect of temperature and salinity on the settlement and survival of copepodids of Lepeophtheirus salmonis (Krøyer, 1837) on Atlantic salmon, Salmo salar L. J. Fish Dis. 23, 309-320.

Venables, W.N., Ripley, B.D., 2003. Modern Applied Statistics with S. Fourth Ed. Springer New York Inc., pp. 498.

Wright, D.W., Oppedal, F., Dempster, T., 2016. Early-stage sea lice recruits on Atlantic salmon are freshwater sensitive. J. Fish Dis. 2016. 
Table 1. Description of salinity metrics used in this investigation.

\begin{tabular}{|c|c|}
\hline Salinity metric & Description \\
\hline \multicolumn{2}{|l|}{ Short-term window } \\
\hline Salinity t-0 & Salinity value observed the day of the sea lice sampling event. \\
\hline Salinity $\mathrm{t}-1$ & Salinity value observed one day before the sea lice sampling event. \\
\hline Salinity $\mathrm{t}-2$ & Salinity value observed two days before the sea lice sampling event. \\
\hline Salinity $\mathrm{t}-3$ & Salinity value observed three days before the sea lice sampling event. \\
\hline Salinity $\mathrm{t}-4$ & Salinity value observed four days before the sea lice sampling event. \\
\hline Salinity t-5 & Salinity value observed five days before the sea lice sampling event. \\
\hline Mean salinity & Arithmetic mean of daily salinity values in the window. \\
\hline $\begin{array}{l}\text { Days below the } \\
\text { salinity threshold }\end{array}$ & $\begin{array}{l}\text { Number of days that salinity levels dropped below a critical threshold in the } \\
\text { window. }\end{array}$ \\
\hline $\begin{array}{l}\text { Drops below the } \\
\text { salinity threshold }\end{array}$ & $\begin{array}{l}\text { Sum of differences between a critical threshold and daily salinity values in the } \\
\text { window. }\end{array}$ \\
\hline $\begin{array}{l}\text { Time-weighted days } \\
\text { below the salinity } \\
\text { threshold }\end{array}$ & $\begin{array}{l}\text { Sum of time-weighted days that salinity levels dropped below a critical } \\
\text { threshold in the window, using a power distance weight function, with alpha } \\
\text { equal to } 0.3,0.5,1.0,1.5,2.0 \text {, or } 3.0 \text {. }\end{array}$ \\
\hline $\begin{array}{l}\text { Time-weighted } \\
\text { drops below the } \\
\text { salinity threshold }\end{array}$ & $\begin{array}{l}\text { Sum of time-weighted differences between a critical threshold and daily salinity } \\
\text { values in the window, using a power distance weights function, with alpha equal } \\
\text { to } 0.3,0.5,1.0,1.5,2.0 \text {, or } 3.0 \text {. }\end{array}$ \\
\hline \multicolumn{2}{|c|}{ Mid-, long-, and longer-term windows } \\
\hline Mean salinity & Arithmetic mean of daily salinity values \\
\hline $\begin{array}{l}\text { Days below the } \\
\text { salinity threshold }\end{array}$ & $\begin{array}{l}\text { Number of days that salinity levels dropped below a critical threshold in the } \\
\text { window. }\end{array}$ \\
\hline $\begin{array}{l}\text { Drops below the } \\
\text { salinity threshold }\end{array}$ & $\begin{array}{l}\text { Sum of differences between a critical threshold and daily salinity values in the } \\
\text { window. }\end{array}$ \\
\hline
\end{tabular}

Note 1: All salinity metrics were calculated for values taken at depths of both 1 and 5 metres.

Note 2: The critical thresholds explored for salinity were 15, 20, and $30 \mathrm{ppt}$.

Note 3: When the difference between the threshold and a daily salinity value was negative, this difference was set to zero. 
Table 2. Participating farms that were active during the study period.

\begin{tabular}{cccccc}
\hline Year & F1 & F2 & F3 & F4 & F5 \\
\hline 2003 & & & & X & \\
2004 & & & & X & \\
2005 & X & & & X & X \\
2006 & X & & & X & X \\
2007 & X & X & & X & X \\
2008 & X & X & X & X & X \\
2009 & X & X & X & & X \\
2010 & X & X & X & & X \\
2011 & X & X & X & X & X \\
2012 & X & X & & X & X \\
2013 & & X & X & X & X \\
2014 & & X & X & X & X \\
2015 & X & X & X & X & X \\
\hline
\end{tabular}

Table 3. Pre-mobile and total mobile L. salmonis mean, median, and $90 \%$ range of abundance values by farm.

\begin{tabular}{lrrrrrrr}
\hline \multirow{2}{*}{ Site } & \multirow{3}{*}{$\mathrm{n}$} & \multicolumn{2}{c}{ Pre-mobile L. salmonis per fish } & \multicolumn{3}{c}{ Total mobile L. salmonis per fish } \\
& & Mean & Median & 90\% Range & Mean & Median & 90\% Range \\
\hline F1 & 77 & 0.097 & 0.017 & $0.00-0.63$ & 0.870 & 0.476 & $0.02-3.03$ \\
F2 & 81 & 0.038 & 0.000 & $0.00-0.07$ & 0.826 & 0.400 & $0.02-3.27$ \\
F3 & 75 & 0.027 & 0.000 & $0.00-0.03$ & 0.645 & 0.365 & $0.00-2.46$ \\
F4 & 106 & 0.098 & 0.000 & $0.00-0.40$ & 0.893 & 0.475 & $0.00-3.19$ \\
F5 & 105 & 0.027 & 0.000 & $0.00-0.14$ & 1.272 & 0.667 & $0.12-5.08$ \\
Overall & 444 & 0.058 & 0.000 & $0.00-0.25$ & 0.925 & 0.483 & $0.00-3.31$ \\
\hline
\end{tabular}


Table 4. Water salinity (ppt) at different depths.

\begin{tabular}{lrrrrrcc}
\hline \multirow{2}{*}{$\begin{array}{l}\text { Depth } \\
(\mathrm{m})\end{array}$} & \multirow{2}{*}{$\mathrm{n}$} & \multirow{2}{*}{ Mean } & \multirow{2}{*}{ SD } & \multirow{2}{*}{ Range } & \multicolumn{3}{c}{ Percentiles } \\
\cline { 6 - 8 } & & & & & $25 \%$ & $50 \%$ & $75 \%$ \\
\hline 5 & 12334 & 20.3 & 7.29 & $0-36$ & 15 & 20 & 26 \\
10 & 9682 & 30.2 & 2.95 & $2-36$ & 26 & 29 & 30 \\
15 & 8975 & 30.5 & 2.27 & $0-36$ & 30 & 30 & 32 \\
\hline
\end{tabular}


Table 5. AIC and AIC difference ( $\triangle \mathrm{AIC}$ ) values between the top-ranked model (shown in Table $6)$ and models using different salinity and temperature metrics ( 1 metre depth) $(n=268)$. A selection of salinity metrics based on the $30 \mathrm{ppt}$ threshold are presented, along with the best performing salinity metric built on the $15 \mathrm{ppt}$ threshold.

\begin{tabular}{|c|c|c|c|}
\hline Model & Metric & AIC & $\Delta \mathrm{AIC}$ \\
\hline \multicolumn{4}{|c|}{ A) Salinity } \\
\hline \multicolumn{4}{|c|}{ Short-term window } \\
\hline 1 & Salinity t-0 & 607.2 & 0.0 \\
\hline 2 & Time-weighed $(\alpha=3.0)$ sum of daily salinity drops below $30 \mathrm{ppt}$ & 607.3 & 0.1 \\
\hline 3 & Time-weighed ( $\alpha=1.5$ ) sum of daily salinity drops below $30 \mathrm{ppt}$ & 609.0 & 1.8 \\
\hline 4 & Time-weighed $(\alpha=0.5)$ sum of daily salinity drops below $30 \mathrm{ppt}$ & 611.9 & 4.7 \\
\hline 5 & Mean salinity & 612.4 & 5.2 \\
\hline 6 & Time-weighed $(\alpha=1.5)$ sum of daily salinity drops below $15 \mathrm{ppt}$ & 612.6 & 5.4 \\
\hline 7 & Sum of daily salinity drops below $30 \mathrm{ppt}$ & 614.5 & 7.3 \\
\hline 8 & No salinity metric in the short-term window & 615.2 & 8.0 \\
\hline \multicolumn{4}{|c|}{ Mid-term window } \\
\hline 1 & Mean salinity & 607.2 & 0.0 \\
\hline 2 & Sum of daily salinity drops below $30 \mathrm{ppt}$ & 607.6 & 0.4 \\
\hline 4 & Sum of days that salinity dropped below $30 \mathrm{ppt}$ & 616.2 & 9.0 \\
\hline 5 & Sum of days that salinity dropped below $15 \mathrm{ppt}$ & 618.5 & 11.3 \\
\hline 6 & No salinity metric in the mid-term window & 627.7 & 20.5 \\
\hline \multicolumn{4}{|c|}{ Long-term window } \\
\hline 1 & No salinity metric in the long-term window & 607.2 & 0.0 \\
\hline 2 & Sum of days that salinity dropped below $30 \mathrm{ppt}$ & 607.5 & 0.3 \\
\hline 3 & Sum of days that salinity dropped below $15 \mathrm{ppt}$ & 607.9 & 0.7 \\
\hline 4 & Sum of daily salinity drops below $30 \mathrm{ppt}$ & 608.2 & 1.0 \\
\hline 5 & Mean salinity & 608.3 & 1.1 \\
\hline \multicolumn{4}{|c|}{ Longer-term window } \\
\hline 1 & Mean salinity & 607.2 & 0.0 \\
\hline 2 & Sum of daily salinity drops below $30 \mathrm{ppt}$ & 609.8 & 2.6 \\
\hline 3 & Sum of days that salinity dropped below $15 \mathrm{ppt}$ & 611.8 & 4.6 \\
\hline 4 & No salinity metric in the longer-term window & 613.6 & 6.4 \\
\hline 5 & Sum of days that salinity dropped below $30 \mathrm{ppt}$ & 615.0 & 7.8 \\
\hline \multicolumn{4}{|c|}{ B) Mean temperature } \\
\hline 1 & Longer-term window & 607.2 & 0.0 \\
\hline 2 & No temperature metric & 609.3 & 2.1 \\
\hline 3 & Long-term window & 610.8 & 3.6 \\
\hline 4 & Mid-term window & 612.0 & 4.8 \\
\hline 5 & Short-term window & 613.3 & 6.1 \\
\hline
\end{tabular}


Table 6. Final model showing the effect of different water salinity metrics, water temperature, EMB treatments, and mean fish weight on log-transformed, total mobile lice abundance in Muchalat Inlet, British Columbia, Canada, from 2007 to 2015 ( $\mathrm{n}=278$ ).

\begin{tabular}{|c|c|c|c|c|c|}
\hline Variable name & $\begin{array}{c}\text { Period } \\
\text { (relative to sampling } \\
\text { event) } \\
\end{array}$ & $\begin{array}{l}\text { Coefficient } \\
\text { estimate }\end{array}$ & $\begin{array}{l}\text { Standard } \\
\text { error }\end{array}$ & $p$-value & $\begin{array}{c}\text { Standardized } \\
\text { coefficient } \\
\text { estimate } \\
\end{array}$ \\
\hline \multicolumn{6}{|l|}{ Fixed effect parameters } \\
\hline Intercept & & -3.394 & 0.422 & $<0.001$ & -0.087 \\
\hline Salinity level (ppt) & same day & 0.017 & 0.006 & 0.006 & 0.111 \\
\hline Mean salinity (ppt) & 15 to 45 days before & 0.061 & 0.013 & $<0.001$ & 0.274 \\
\hline Mean salinity (ppt) & 61 to 75 days before & 0.022 & 0.009 & 0.022 & 0.108 \\
\hline Mean temperature $\left({ }^{\circ} \mathrm{C}\right)$ & 61 to 75 days before & 0.066 & 0.031 & 0.034 & 0.181 \\
\hline Mean fish weight (kg) & same day & 0.113 & 0.055 & 0.040 & 0.175 \\
\hline EMB treatment (yes) & 15 to 80 days before & -0.430 & 0.147 & 0.003 & -0.151 \\
\hline \multicolumn{6}{|c|}{ Random effect parameters } \\
\hline Fish production cycle $(\mathrm{v}$ & ance) & - & - & & \\
\hline $\begin{array}{l}\text { Residual structure: expo } \\
\text { rho } \\
\text { variance }\end{array}$ & tial & $\begin{array}{l}0.973 \\
0.841 \\
\end{array}$ & $\begin{array}{l}0.004 \\
0.100 \\
\end{array}$ & & \\
\hline
\end{tabular}




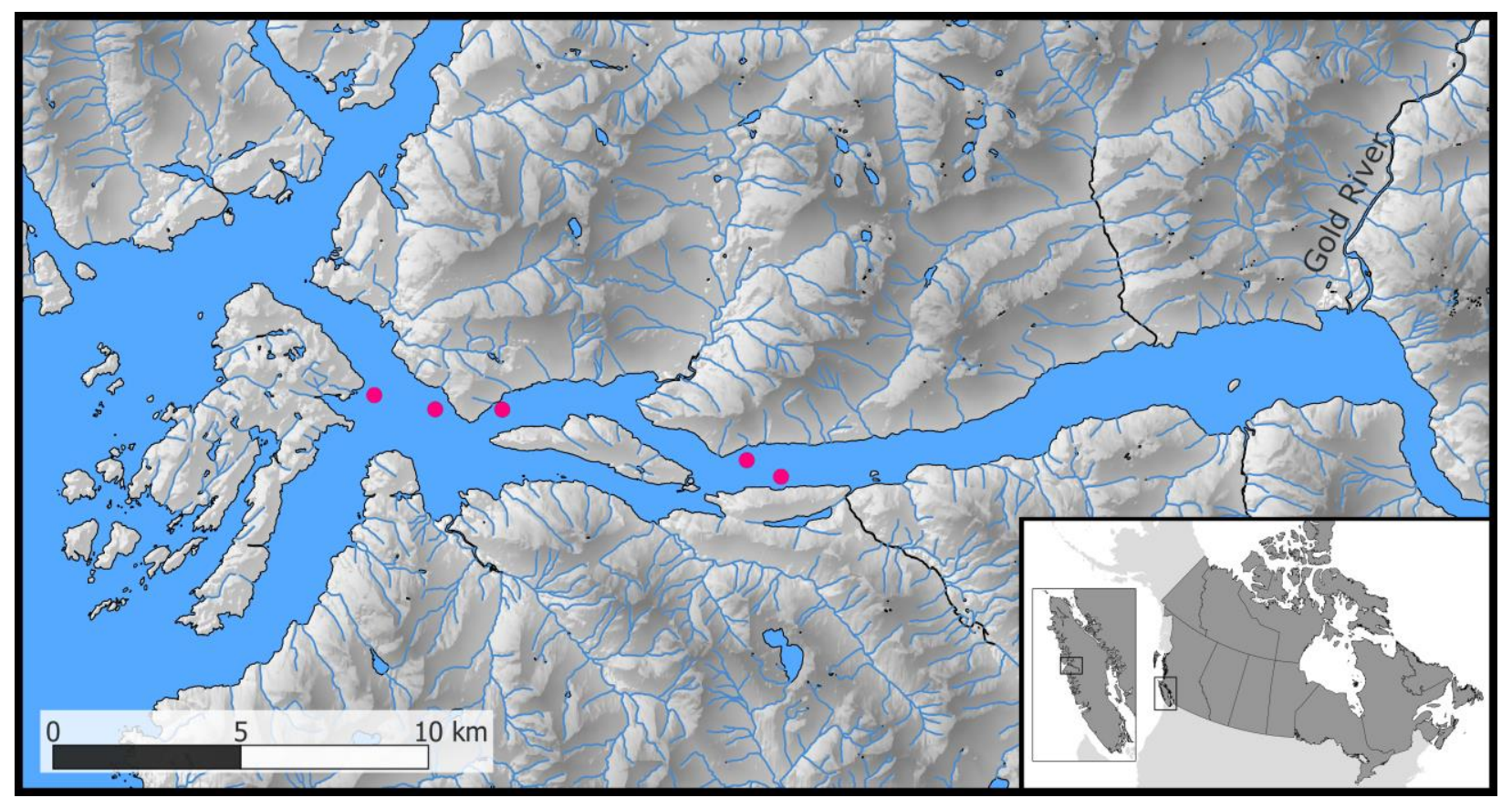

Figure 1. The Muchalat Inlet, British Columbia, Canada, and active salmon farm locations (red points) at various time periods from 2003 to 2015 . 


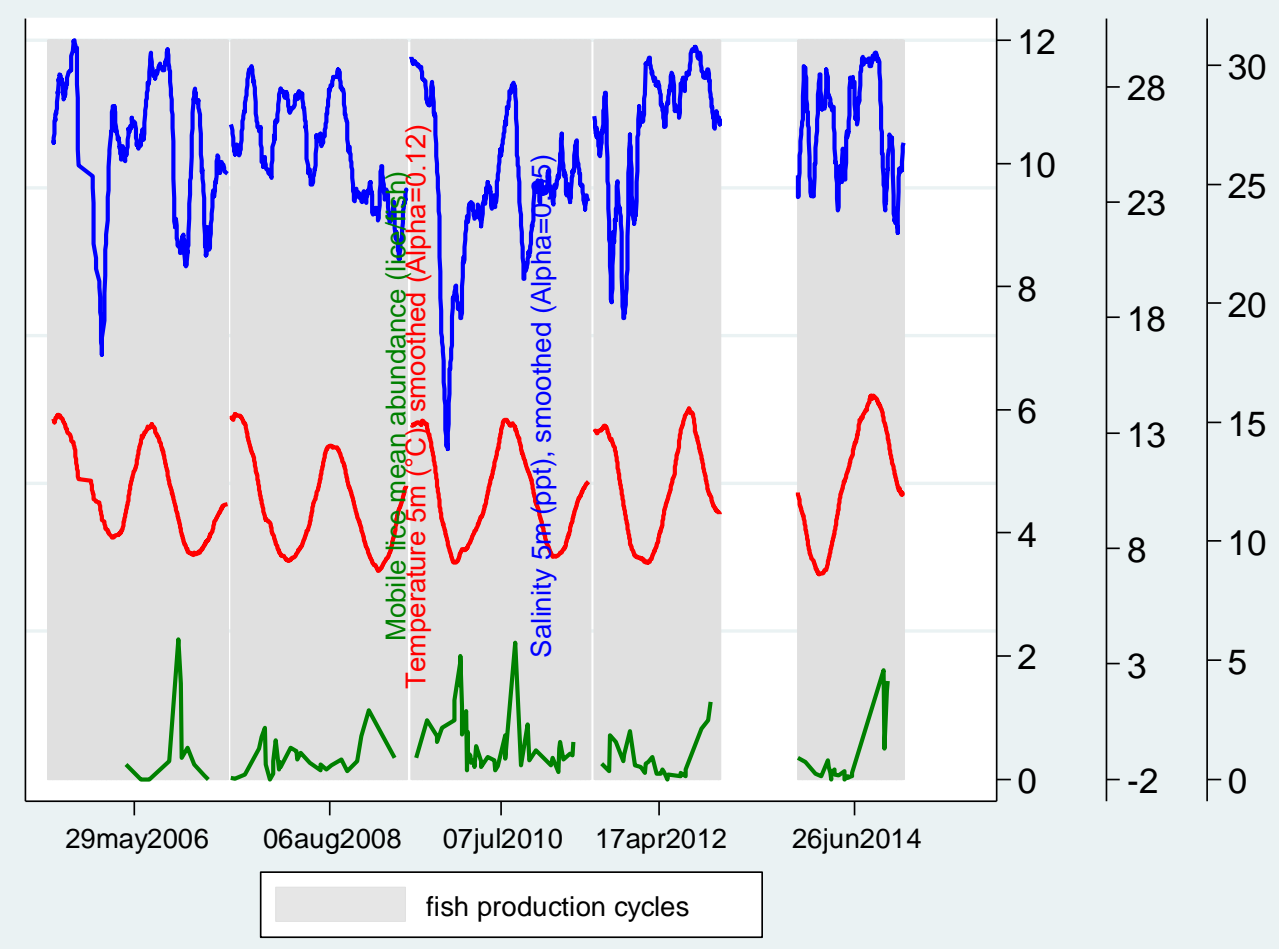

Figure 2. Smoothed water salinity (ppt) and temperature $\left({ }^{\circ} \mathrm{C}\right)$ profiles recorded at 5 metre depth, and mobile L. salmonis mean abundance (lice/fish) for five fish production cycles of farm F5 that took place from 2005 to 2015 . 


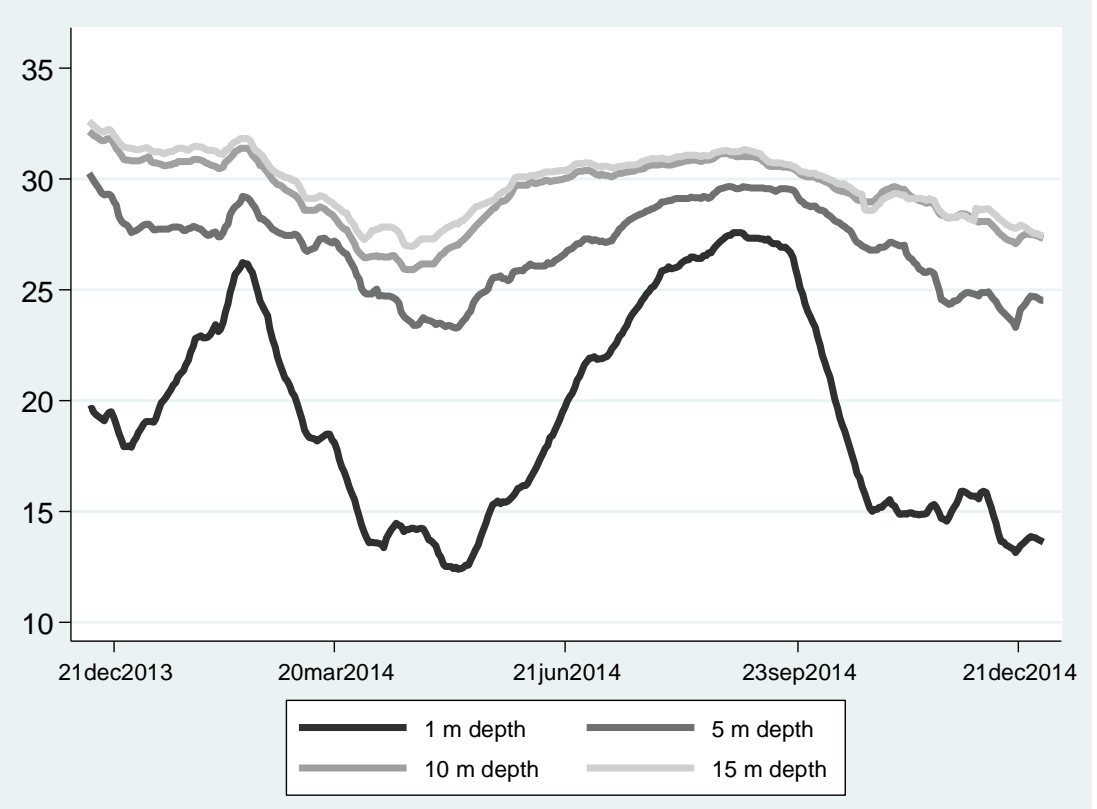

Figure 3a. Water salinity profiles (ppt) recorded at 1, 5, 10 and 15 metre depth at farm F3 from December 2013 to December 2014.

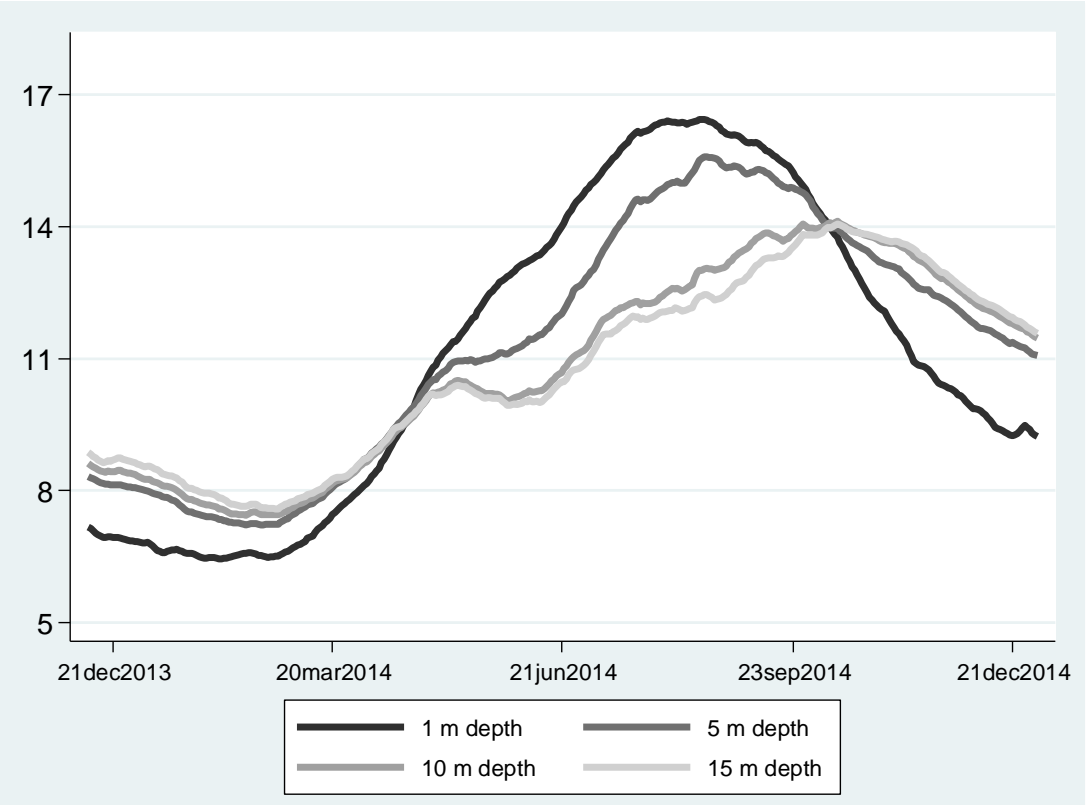

Figure $3 \mathrm{~b}$. Water temperature profiles $\left({ }^{\circ} \mathrm{C}\right)$ recorded at 1, 5, 10 and 15 metre depth at farm $\mathrm{F} 3$ from December 2013 to December 2014. 